\title{
Association of plasma potassium with mortality and end-stage kidney disease in patients with chronic kidney disease under nephrologist care - The NephroTest study
}

Sandra Wagner ${ }^{1,2}$, Marie Metzger ${ }^{1}$, Martin Flamant ${ }^{3}$, Pascal Houillier ${ }^{4,5}$, Jean-Philippe Haymann ${ }^{6}$, François Vrtovsnik ${ }^{3}$, Eric Thervet ${ }^{5,7}$, Jean-Jacques Boffa ${ }^{6}$, Ziad A. Massy ${ }^{1,2,8}$, Bénédicte Stengel ${ }^{1,2^{*}}$,

Patrick Rossignol ${ }^{2,9}$ and for the NephroTest Study group

\begin{abstract}
Background: Low and high blood potassium levels are common and were both associated with poor outcomes in patients with chronic kidney disease (CKD). Whether such relationships may be altered in CKD patients receiving optimized nephrologist care is unknown.

Methods: NephroTest is a hospital-based prospective cohort study that enrolled 2078 nondialysis patients (mean age: $59 \pm 15$ years, 66\% men) in CKD stages 1 to 5 who underwent repeated extensive renal tests including plasma potassium $\left(P_{K}\right)$ and glomerular filtration rate (GFR) measured (mGFR) by ${ }^{51} \mathrm{Cr}$-EDTA renal clearance. Test reports included a reminder of recommended targets for each abnormal value to guide treatment adjustment. Main outcomes were cardiovascular (CV) and all-cause mortality before end-stage kidney disease (ESKD), and ESKD.

Results: At baseline, median $\mathrm{mGFR}$ was $38.4 \mathrm{~mL} / \mathrm{min} / 1.73 \mathrm{~m}^{2}$; prevalence of low $\mathrm{P}_{\mathrm{K}}(<4 \mathrm{mmol} / \mathrm{L})$ was $26.5 \%$, and of high $\mathrm{P}_{\mathrm{K}}$ (>5 mmol/L) 6.4\%; 74.4\% of patients used angiotensin converting enzyme inhibitors (ACEi) or angiotensin receptor blockers (ARB). After excluding 137 patients with baseline GFR $<10 \mathrm{~mL} / \mathrm{min} / 1.73 \mathrm{~m}^{2}$ or lost to follow-up, 459 ESKD events and 236 deaths before ESKD (83 CV deaths) occurred during a median follow-up of 5 years. Compared to patients with $P_{K}$ within $[4,5] \mathrm{mmol} / \mathrm{L}$ at baseline, those with low $\mathrm{P}_{\mathrm{K}}$ had hazard ratios (HRs) [95\% Cl] for all-cause and CV mortality before ESKD, and for ESKD of 0.82 [0.58-1.16], 1.01 [0.52-1.95], and 1.14 [0.89-1.47], respectively, with corresponding figures for those with high $P_{k}$ of 0.79 [0.48-1.32], 1.5 [0.69-3.3], and 0.92 [0.70-1.21]. Considering time-varying $P_{k}$ did not materially change these findings, except for the HR of ESKD associated with high $P_{K}, 1.39$ [1.09-1.78]. Among 1190 patients with at least two visits, $P_{K}$ had normalized at the second visit in 39.9 and $54.1 \%$ respectively of those with baseline low and high $P_{k}$. Among those with low $P_{k}$ that normalized, ARB or ACEi use increased between the visits (68.3\% vs $81.8 \%, P<.0001)$, and among those with high $P_{K}$ that normalized, potassium-binding resin and bicarbonate use increased (13.0\% vs 37.0\%, $P<.001$, and $4.4 \%$ vs $17.4 \%$, $P=0.01$, respectively) without decreased ACEi or ARB use.
\end{abstract}

Conclusion: In these patients under nephrology care, neither low nor high $\mathrm{P}_{\mathrm{k}}$ was associated with excess mortality.

Keywords: Plasma potassium, Hypokalemia, Hyperkalemia, Chronic kidney disease, End-stage kidney disease, Mortality, Cardiovascular mortality

\footnotetext{
* Correspondence: benedicte.stengel@inserm.fr

'CESP, Inserm U1018, Univ Paris-Saclay, Univ Paris-Sud, UVSQ, Villejuif, France

${ }^{2}$ FCRIN INI-CRCT, Paris, France

Full list of author information is available at the end of the article
} 


\section{Background}

The mainstays of nonspecific secondary prevention of chronic kidney disease (CKD) progression, irrespective of cause, include blood pressure control and proteinuriadirected strategies to preserve residual kidney function, with special emphasis on angiotensin-converting enzyme inhibitors (ACEi) or angiotensin-receptor blockers (ARB) [1-4]. However, fear of inducing hyperkalemia, an inherent risk associated with the mechanism of action of these drugs, may limit their initiation or dose increases, given the considerable attention paid to this risk, especially in patients with $C K D$, diabetes mellitus, and or heart failure (HF) [5-8]. Although the exact serum $\left(\mathrm{S}_{\mathrm{K}}\right)$ or plasma potassium $\left(\mathrm{P}_{\mathrm{K}}\right)$ concentration associated with increased mortality remains controversial, growing evidence suggests that in patients with CKD, diabetes mellitus, or HF, especially the elderly, a $S_{\mathrm{K}}>5.0 \mathrm{mmol} / \mathrm{L}$ is associated with a higher risk of death $[9,10]$. Moreover, a post-hoc analysis of the Reduction of Endpoints in non-insulin-dependent diabetes mellitus with the Angiotensin II Antagonist Losartan (RENAAL) trial showed that increased $\mathrm{S}_{\mathrm{K}}$ concentrations $\geq 5.0 \mathrm{mmol} / \mathrm{L}$ at 6 months were associated with an increased risk of doubled serum creatinine or end-stage kidney disease (ESKD), independent of baseline renal function and other important predictors of renal outcomes [11].

Low $S_{K}<4 \mathrm{mmol} / \mathrm{L}$ has also been associated with excess mortality and hospitalization, especially for patients with CKD and HF [12], for whom the relation between $\mathrm{S}_{\mathrm{K}}$ and mortality is U-shaped [13]. The frequent concomitant use of non-potassium-sparing (thiazide and loop) diuretics may induce low $\mathrm{S}_{\mathrm{K}}$ in CKD patients, and again a U-shaped relation has been observed between $S_{K}$ and mortality, with mortality risk significantly greater at $\mathrm{S}_{\mathrm{K}}<4.0 \mathrm{mmol} / \mathrm{L}$ than at 4.0 to $5.5 \mathrm{mmol} / \mathrm{L}$. In this CKD cohort, only the composite of cardiovascular events or death as an outcome was associated with elevated $\mathrm{S}_{\mathrm{K}}$ (>5.5) [14]. Risk for ESKD was also elevated at $\mathrm{S}_{\mathrm{K}}<4 \mathrm{mmol} / \mathrm{L}$. Hayes et al. reported a significant nonlinear association between $S_{K}$ and all-cause mortality in a retrospective CKD survey; regression splines showed that mortality increased in association with both high and low $S_{K}$ levels [15]. Other studies in CKD patients have also shown low $\mathrm{S}_{\mathrm{K}}(<3.5 \mathrm{mmol} / \mathrm{L})$ is associated with excess mortality [4] and ESKD risk [16]. Another study found low $\mathrm{S}_{\mathrm{K}}(<4 \mathrm{mmol} / \mathrm{L})$ associated with mortality in patients with CKD but not with ESKD [17]. Higher $S_{K}$ $(>5 \mathrm{mmol} / \mathrm{L}$ ) was associated with excess ESKD in one study [16] but not another [17]. Nevertheless, it appears that high $\mathrm{S}_{\mathrm{K}}(>5,5.6$ or $6 \mathrm{mmol} / \mathrm{L})$ is associated with excess mortality $[4,17]$. Of note, all these studies reported to have measured $S_{K}$ which is known to overestimate potassium concentration on average by $0.4 \mathrm{mmol} / \mathrm{L}$ as compared with plasma potassium $\left(\mathrm{P}_{\mathrm{K}}\right)$ which reduces the risk for blood coagulation $[18,19]$.
In this study, we aimed to evaluate the association of $\mathrm{P}_{\mathrm{K}}$ with renal and cardiovascular outcomes, along with treatment practice patterns in the use of drugs apt to modulate $\mathrm{P}_{\mathrm{K}}$ in a cohort of patients with CKD under optimized nephrologist care, characterized by repeated extensive laboratory work-ups.

\section{Population and methods \\ Study population}

NephroTest is a prospective hospital-based cohort study that enrolled 2084 adult patients with any diagnosis of CKD stages 1-5 referred by nephrologists to three departments of physiology for extensive work-ups between January 2000 and December 2012 [20]. The NephroTest work-up was designed to optimize CKD care by providing nephrologists with a large set of blood and urine tests to assess each patient's metabolic complications and cardiovascular risk at yearly intervals. Laboratory report notified any relevant abnormal values, such as $\mathrm{P}_{\mathrm{K}}$ lower than 3.5 or higher than $5.0 \mathrm{mmol} / \mathrm{L}$, together with a reminder of current recommended targets, to guide treatment adjustment [20].

Eligible patients were $\geq 18$ years of age, not pregnant, not on dialysis, and not living with a kidney transplant. After exclusion of 6 patients with missing data for $P_{K}$ or treatment at baseline, this analysis included 2078 patients (Additional file 1: Figure S1).

\section{Measurements}

Clinical and laboratory data were recorded during a 5-h in-person visit at enrollment and during follow-up. They included demographics, renal diagnosis, medical history, height and weight, resting blood pressure, and medications. We collected blood and urine samples to determine levels of $\mathrm{P}_{\mathrm{K}}$, venous $\mathrm{CO} 2, \mathrm{HbA} 1 \mathrm{c}$, and albumin, as well as urinary creatinine, albumin, and potassium. $\mathrm{P}_{\mathrm{K}}$ status was studied in three categories: $<4 \mathrm{mmol} / \mathrm{L}$ (low $\mathrm{P}_{\mathrm{K}}$ ), 4-5 mmol/L (normal $\mathrm{P}_{\mathrm{K}}$ ), and $>5 \mathrm{mmol} / \mathrm{L}$ (high $\mathrm{P}_{\mathrm{K}}$ ). Diabetes was defined as either fasting glycemia $\geq 7 \mathrm{mmol} / \mathrm{L}$ or $\mathrm{HbA} 1 \mathrm{c} \geq 6.5 \%$ or antidiabetic treatment. At each visit, GFR was measured by ${ }^{51} \mathrm{Cr}$-EDTA renal clearance. Briefly, 1.8-3.5 MBq of ${ }^{51} \mathrm{Cr}$-EDTA (GE Healthcare, Velizy, France) was injected intravenously as a single bolus. An hour was allowed for distribution of the tracer in the extracellular fluid, and then the average renal ${ }^{51} \mathrm{Cr}$-EDTA clearance was determined for five to six consecutive 30-min clearance periods. Over the study period, patients underwent a total of 5523 laboratory visits, and a median of 2 [IQR, 1-4] per patient); 1190 patients (57\%) had at least two visits.

\section{Outcomes}

The primary endpoints were ESKD, defined by dialysis start or preemptive kidney transplantation, and pre-ESKD 
all-cause mortality. The secondary endpoints were preESKD cardiovascular (CV) mortality and all-cause death, regardless of ESKD. Events were identified either from patients' medical records or through record linkage with the national REIN (Renal Epidemiology and Information Network) registry of treated ESKD and the national death registry. All survival data were right-censored on December 31, 2013, or to the date of last visit for patients not identified in registries. Cardiovascular causes of death included ischemic heart disease, cerebrovascular disease, HF, dysrhythmia, peripheral arterial disease, sudden death, and valvular disease. Patients were followed up through December 31, 2013. These outcomes were studied in 1941 patients after exclusion of 137 with baseline GFR $<10 \mathrm{ml} /$ $\mathrm{min} / 1,73 \mathrm{~m}^{2}$ or lost to follow-up from the initial sample (Additional file 1: Figure S1).

\section{Statistical analyses}

In the overall population, we first used analysis of variance (ANOVA), the Kruskal-Wallis test, or the chi-square test, as appropriate, to compare patients' baseline characteristics by $\mathrm{P}_{\mathrm{K}}$ status subgroup. We then used multinomial logistic regression models to estimate odds ratios (OR) and their 95\% confidence intervals $(95 \% \mathrm{CI})$ for low and high $\mathrm{P}_{\mathrm{K}}$ associated with baseline characteristics, with normokalemia as the reference category.

Second, we performed Cox regression models to estimate crude and adjusted cause-specific hazard ratios (HR) and their 95\% confidence intervals (95\% CI) for ESKD, and pre-ESKD all-cause and CV mortality associated with $\mathrm{P}_{\mathrm{K}}$ status at baseline, with normokalemia [4-5 mmol/L] as the reference category. In each of these models, the competing events were treated as censored observations [21]. Adjustment covariates were similar in all analyses: age, center, sex, ethnicity, smoking status, body mass index (BMI), diabetes, baseline mGFR, albuminemia, urinary potassium, log albumin/creatinine ratio, medication that may decrease $\mathrm{P}_{\mathrm{K}}$ (nonpotassium-sparing diuretics, bicarbonate treatment, potassium-binding resins), and medication that may increase $P_{K}$ (potassium-sparing diuretics, ACEi or ARBs, $\beta$-blockers). We tested the proportionalhazard assumption with Schoenfeld residuals against time for each covariate; because it was not satisfied for mGFR in the cause-specific Cox model with ESKD, we stratified rather than adjusted for baseline mGFR level, using six classes of mGFR $(10-20,20-30,30-40,40-50,50-60$, $>60 \mathrm{~mL} / \mathrm{min}$ per $\left.1.73 \mathrm{~m}^{2}\right)$. To account for changes in $\mathrm{P}_{\mathrm{K}}$ over time, we used time-dependent Cox models to estimate crude and adjusted HRs for each outcome associated with $\mathrm{P}_{\mathrm{K}}$ during follow-up. In the time-dependent analysis, medications were also updated at each visit. Finally, penalized splines were used in fully adjusted time-dependent Cox models to represent the functional relation between $\mathrm{P}_{\mathrm{K}}$ measurements and the risk of each outcome.
Third, we described changes in $\mathrm{P}_{\mathrm{K}}$ status between the first and the second visit in the subpopulation of patients with at least two visits as well as changes in medication between the visits for patients with low or high $\mathrm{P}_{\mathrm{K}}$ at baseline that normalized at the second visit. Changes were tested with McNemar's test.

Statistical analyses were performed with SAS version 9.4 (SAS Institute, Cary, NC) and R version 3.0.2.

\section{Results \\ Baseline characteristics}

The participants' mean age at baseline was $58.8 \pm 15.2$ years, and the median mGFR $38.9(27.2-53.8) \mathrm{mL} / \mathrm{min}$ per $1.73 \mathrm{~m}^{2} ; 21.8,21.1,29.3,22.0$, and $5.7 \%$ of patients were in CKD stages $2,3 \mathrm{a}, 3 \mathrm{~b}, 4$, and 5 , respectively. $\mathrm{P}_{\mathrm{K}}$ values ranged from 2.40 to $7.30 \mathrm{mmol} / \mathrm{L}$, with a mean of $4.26 \pm 0.50 \mathrm{mmol} / \mathrm{L}$ and a median of 4.20 (3.92-4.52). ACEi or ARB were prescribed to $74.4 \%$ of patients (Table 1). The distribution of $P_{K}$ status is shown in Additional file 2: Figure S2. The prevalence of high $\mathrm{P}_{\mathrm{K}}$ $(>5 \mathrm{mmol} / \mathrm{L})$ was $8.3 \%$, and that of low $\mathrm{P}_{\mathrm{K}}(<4 \mathrm{mmol} / \mathrm{L})$ $27.2 \%$ (3.9\% for very low $P_{K}<3.5 \mathrm{mmol} / \mathrm{L}$ ).

Patients with high $\mathrm{P}_{\mathrm{K}}$ tended to be younger, more frequently men, with a history of cardiovascular disease, diabetes, lower mGFR, and higher albuminuria, and more frequent prescriptions for $\mathrm{ACEi}, \mathrm{ARB}$, bicarbonates, or potassium-binding resins (Table 1 ). Those with low $\mathrm{P}_{\mathrm{K}}$ were younger, more often women, and had prescriptions for those medications less often. In multivariable analyses (Table 2), higher ORs of high $P_{K}$ were significantly associated with diabetes, current smoking, lower mGFR, and prescriptions for $\mathrm{P}_{\mathrm{K}}$-increasing medication (i.e., ACEi or ARB or potassium-sparing diuretics), and lower ORs with older age and female gender. In contrast, higher ORs of low $\mathrm{P}_{\mathrm{K}}$ were significantly associated with female gender and use of potassium-lowering medication, and lower Ors with lower mGFR, CVD history, and potassium-increasing medication.

\section{Association of $\mathrm{P}_{\mathrm{K}}$ status with ESKD and pre-ESKD mortality}

Over a median follow-up of 5 years, 459 of the 1941 patients included in this analysis began RRT for ESKD, and 236 died before starting RRT, 83 of them from CV causes. Compared to patients with normokalemia at baseline, those with low $\mathrm{P}_{\mathrm{K}}$ had crude/adjusted HRs [95\% CI] for ESKD and for all-cause and CV mortality before ESKD of: $0.61[0.48-0.78] / 1.14[0.89-1.47,0.58[0.42-0.80] / 0.82[0.58-$ $1.16]$, and $0.40[0.20-0.78] / 1.01$ [0.52-1.95], and those with high $\mathrm{P}_{\mathrm{K}}, 2.43[1.89-3.13] / 0.92$ [0.70-1.21], 0.97[0.59$1.60] / 0.79$ [0.48-1.32], and 1.41[0.67-2.97]/1.47 [0.673.24], respectively. The main confounder in these associations was mGFR. Considering time-varying $P_{K}$ did not materially change these findings: adjusted HRs $[95 \% \mathrm{CI}]$ for ESKD and for all-cause and CV 
Table 1 Patient characteristics according to baseline plasma potassium concentration $(\mathrm{mmol} / \mathrm{L})$

\begin{tabular}{|c|c|c|c|c|c|}
\hline & \multirow[t]{2}{*}{ Overall (2078) } & \multicolumn{3}{|c|}{ Baseline plasma potassium (mmol/L) } & \multirow[t]{2}{*}{$p$} \\
\hline & & $\begin{array}{l}<4 \\
(n=566)\end{array}$ & $\begin{array}{l}4-5 \\
(n=1340)\end{array}$ & $\begin{array}{l}>5 \\
(n=172)\end{array}$ & \\
\hline \multicolumn{6}{|l|}{ Demographics } \\
\hline Age (years) & $58.8 \pm 15.2$ & $56.0 \pm 15.6$ & $60.2 \pm 14.8$ & $56.9 \pm 15.5$ & $<.001$ \\
\hline Men (\%) & 66.3 & 60.7 & 67.9 & 72.7 & $<.001$ \\
\hline African (\%) & 13.0 & 18.0 & 11.0 & 12.2 & $<.001$ \\
\hline $\mathrm{BMI}\left(\mathrm{kg} / \mathrm{m}^{2}\right)$ & $26.6 \pm 5.2$ & $26.2 \pm 5.4$ & $26.8 \pm 5.1$ & $26.5 \pm 5.2$ & 0.20 \\
\hline Former smokers (\%) & 30.9 & 25.4 & 33.2 & 30.8 & \multirow[t]{2}{*}{$<.001$} \\
\hline Current smokers (\%) & 13.7 & 12.4 & 13.4 & 20.3 & \\
\hline \multicolumn{6}{|l|}{ Clinics } \\
\hline CVD history (\%) & 17.3 & 10.9 & 19.9 & 18.6 & $<.001$ \\
\hline Diabetes (\%) & 29.9 & 25.6 & 30.9 & 37.2 & 0.01 \\
\hline Primary kidney disease (\%) & & & & & $<.001$ \\
\hline Diabetic & 10.1 & 5.1 & 11.1 & 18.6 & \\
\hline Glomerular & 14.1 & 12.4 & 14.3 & 18.6 & \\
\hline Vascular & 26.2 & 26.5 & 26.4 & 23.3 & \\
\hline Polycystic & 5.5 & 9.0 & 4.3 & 3.5 & \\
\hline Interstitial & 9.0 & 9.9 & 8.8 & 7.6 & \\
\hline Other or unknown & 35.0 & 37.1 & 35.0 & 28.5 & \\
\hline \multicolumn{6}{|l|}{ Measurements } \\
\hline Systolic BP (mm Hg) & $136.0 \pm 20.4$ & $134.7 \pm 20.7$ & $136.2 \pm 20.8$ & $138.8 \pm 21.4$ & 0.07 \\
\hline Diastolic BP (mm Hg) & $74.8 \pm 11.6$ & $75.5 \pm 12.2$ & $74.5 \pm 11.5$ & $76.1 \pm 10.3$ & 0.13 \\
\hline Mean BP (mmHg) & $95.3 \pm 13.3$ & $95.3 \pm 14$ & $95.0 \pm 13.0$ & $97.0 \pm 12.6$ & 0.48 \\
\hline $\mathrm{mGFR}\left(\mathrm{ml} / \mathrm{min} / 1.73 \mathrm{~m}^{2}\right)$ & $38.9(27.2-53.8)$ & $47.9(35.7-64.2)$ & $37.6(26.7-51.7)$ & $24.7(16.4-34.3)$ & $<.001$ \\
\hline Albuminemia (g/L) & $39.4 \pm 4.5$ & $39.4 \pm 4.2$ & $39.4 \pm 4.5$ & $39.3 \pm 5.2$ & 0.72 \\
\hline Albumin/creatinine ratio & $8.9(1.6-50.9)$ & $5.4(1.4-31.7)$ & $9.6(1.5-54.7)$ & $28.0(6.0-98.2)$ & $<.001$ \\
\hline Plasma potassium (mmol/L) & $4.3 \pm 0.5$ & $3.7 \pm 0.2$ & $4.4 \pm 0.3$ & $5.3 \pm 0.4$ & - \\
\hline Urinary potassium (mmol/24 h) & $66.0 \pm 35.1$ & $64.1 \pm 31$ & $62 \pm 26.1$ & $62 \pm 26.1$ & 0.10 \\
\hline \multicolumn{6}{|l|}{ Medication use } \\
\hline ACEi or ARBs (\%) & 74.4 & 65.7 & 76.5 & 86.1 & $<.001$ \\
\hline$\beta$-blockers (\%) & 37.3 & 32.5 & 39.3 & 38.4 & 0.02 \\
\hline Bicarbonate (\%) & 3.8 & 1.6 & 4.1 & 7.6 & $<.001$ \\
\hline Potassium-binding resins (\%) & 6.6 & 2.3 & 7.2 & 16.9 & $<.001$ \\
\hline Potassium non-sparing diuretics $\left.{ }^{\mathrm{a}} \%\right)$ & 46.7 & 48.2 & 45.6 & 50.6 & 0.08 \\
\hline Potassium-sparing diuretics ${ }^{\mathrm{b}}(\%)$ & 3.4 & 4.4 & 3.0 & 2.9 & 0.31 \\
\hline
\end{tabular}

Values are $\%$, mean \pm SD or median (interquartile range)

aLoop or thiazide diuretics. ${ }^{b}$ amiloride or anti-aldosterone diuretics

$A C E i$ angiotensin-converting enzyme inhibitors, $A R B$ s angiotensin II receptor blocker BMI body mass index, CVD cardiovascular disease, BP blood pressure, $m G F R$ measured GFR

mortality before ESKD for those with low $\mathrm{P}_{\mathrm{K}}$ were 1.14 [0.88-1.47], 0.87 [0.62-1.21], and 0.66 [0.441.00], and for those with high $\mathrm{P}_{\mathrm{K}}, 1.39$ [1.09-1.78], $0.96[0.59-1.57]$ and $0.93[0.58-1.50]$, respectively. We found no significant association between $\mathrm{P}_{\mathrm{K}}$ during follow-up and pre-ESKD, overall or CV mortality, or with overall mortality regardless of ESKD (Fig. 1).
HRs for ESKD were slightly but significantly higher at higher $\mathrm{P}_{\mathrm{K}}$ levels $(>5 \mathrm{mmol} / \mathrm{L})$.

\section{Changes in $P_{K}$ status between visits}

At the enrolment visit, $66.4 \%$ of patients were normokalemic, and at the second visit, $64.2 \%$ (Table 3). The median (q1-q3) duration between the first and the second 
Table 2 Odds ratios of low or high plasma potassium associated with baseline patient characteristics - Multinomial logistic regression using patients with plasma potassium of $4-5 \mathrm{mmol} / \mathrm{L}$ as the reference group)

\begin{tabular}{|c|c|c|c|}
\hline & & \multicolumn{2}{|c|}{ Plasma potassium (mmol/L) } \\
\hline & & $<4$ & $>5$ \\
\hline Age (per year) & & $0.99(0.98-1.00)$ & $0.98(0.96-0.99)$ \\
\hline Women vs men & & $1.49(1.16-1.90)$ & $0.47(0.30-0.72)$ \\
\hline Sub-Saharan vs other ethnicity & & $1.35(0.99-1.83)$ & $1.15(0.66-1.99)$ \\
\hline \multicolumn{4}{|l|}{$\operatorname{mGFR}\left(\mathrm{ml} / \mathrm{min} / 1.73 \mathrm{~m}^{2}\right)$} \\
\hline & $<15$ & $0.11(0.05-0.23)$ & $29.65(10.87-80.88)$ \\
\hline & $15-30$ & $0.26(0.18-0.38)$ & $13.58(5.71-32.3)$ \\
\hline & $30-45$ & $0.47(0.34-0.63)$ & $5.70(2.42-13.45)$ \\
\hline & $45-60$ & $0.67(0.49-0.90)$ & $2.70(1.07-6.85)$ \\
\hline & $>60$ & 1 & 1 \\
\hline \multicolumn{4}{|l|}{ BMI } \\
\hline & $<19$ & $1.46(0.83-2.59)$ & $1.49(0.65-3.43)$ \\
\hline & $19-25$ & 1 & 1 \\
\hline & $25-30$ & $0.85(0.66-1.10)$ & $0.78(0.51-1.20)$ \\
\hline & $>30$ & $0.78(0.57-1.07)$ & $1.05(0.65-1.73)$ \\
\hline \multicolumn{4}{|l|}{ Smoking status } \\
\hline & Never smoked & 1 & 1 \\
\hline & Former smoker & $0.85(0.66-1.11)$ & $1.02(0.67-1.54)$ \\
\hline & Active smoker & $0.76(0.54-1.06)$ & $1.66(1.03-2.67)$ \\
\hline Mean blood pressure (per mmHg) & & $1.01(1.00-1.02)$ & $1.01(0.99-1.02)$ \\
\hline Cardio-vascular history & & $0.63(0.46-0.88)$ & $0.81(0.51-1.28)$ \\
\hline \multicolumn{4}{|l|}{ ACR (mg/mmol) } \\
\hline & $<3$ & 1 & 1 \\
\hline & $3-30$ & $1.07(0.82-1.40)$ & $1.25(0.76-2.08)$ \\
\hline & $>30$ & $0.80(0.59-1.10)$ & $1.13(0.67-1.90)$ \\
\hline Diabetes & & $0.86(0.66-1.13)$ & $1.56(1.04-2.34)$ \\
\hline Urine potassium & & $0.99(0.99-1.00)$ & $1.01(1.00-1.01)$ \\
\hline \multicolumn{4}{|l|}{ Serum albumin } \\
\hline & $\geq 35$ & 1 & 1 \\
\hline & $<35$ & $1.23(0.87-1.74)$ & $1.23(0.76-1.98)$ \\
\hline Serum potassium increasing drugs $s^{a}$ & & $0.58(0.44-0.78)$ & $2.50(1.17-5.35)$ \\
\hline Serum potassium-lowering drugs ${ }^{b}$ & & $1.70(1.33-2.17)$ & $1.01(0.69-1.49)$ \\
\hline
\end{tabular}

${ }^{a}$ ACEi or ARBs or potassium-sparing diuretics ${ }^{b}$ loop or thiazide diuretic, kayexalate or bicarbonates $\mathrm{BMI}$, body mass index, CVD, cardiovascular disease, mGFR, measured GFR, ACR, ratio of urinary albumin to creatinine The analyses was adjusted for center

visit was $1.26(1.02-1.92)$ years. Overall, between the two visits, half of the patients remained in the normokalemic subgroup, while $39.9 \%$ of those with low $\mathrm{P}_{\mathrm{K}}$ and $54.1 \%$ of those with high $\mathrm{P}_{\mathrm{K}}$ at baseline had normal $\mathrm{P}_{\mathrm{K}}$ at the second visit. In patients with low $\mathrm{P}_{\mathrm{K}}$ that normalized, ACEi or ARB use increased between the visits $(68.3 \%$ vs $81.8 \%, P<.0001)$ (Figure 2). In those with high $\mathrm{P}_{\mathrm{K}}$ that normalized, use of potassium-binding resins and bicarbonates also rose between visits $(13.0 \%$ vs $37.0 \%, P<0.001$ for potassiumbinding resins, and $4.4 \%$ vs $17.4 \%, P=0.01$ for bicarbonates). The use of ACEi or ARB did not change between the two visits $(80.4 \%$ at visit 1 vs $84.8 \%$ at visit 2 , $P=0.32$ ). Nonetheless, ARB use increased between visits 1 and $2(36.9 \%$ vs $50.0 \%, P=0.03)$.

\section{Discussion}

In this cohort of CKD patients under nephrologist care, low $\mathrm{P}_{\mathrm{K}}(<4 \mathrm{mmol} / \mathrm{L})$ was relatively common, but hypokalemia $(<3.5 \mathrm{mmol} / \mathrm{L})$ and high $\mathrm{P}_{\mathrm{K}}$ uncommon. Neither high nor low $\mathrm{P}_{\mathrm{K}}$, at baseline or during 


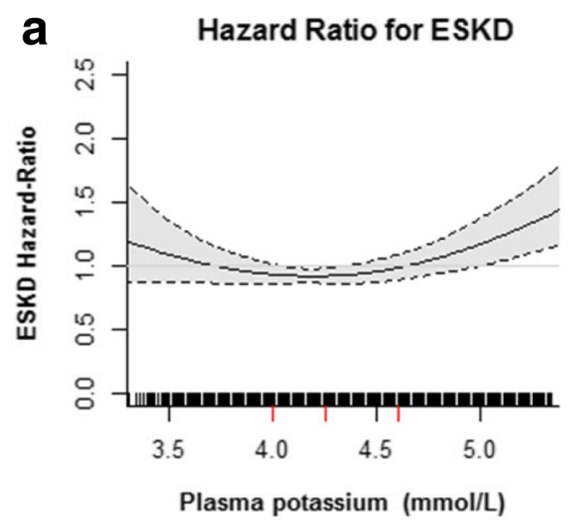

C Hazard Ratio for pre-ESKD CV death

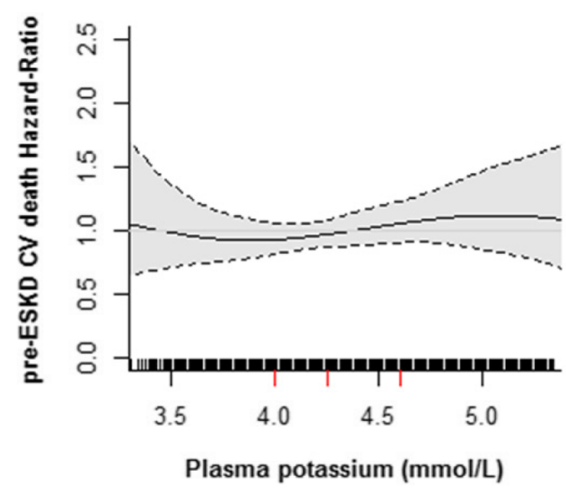

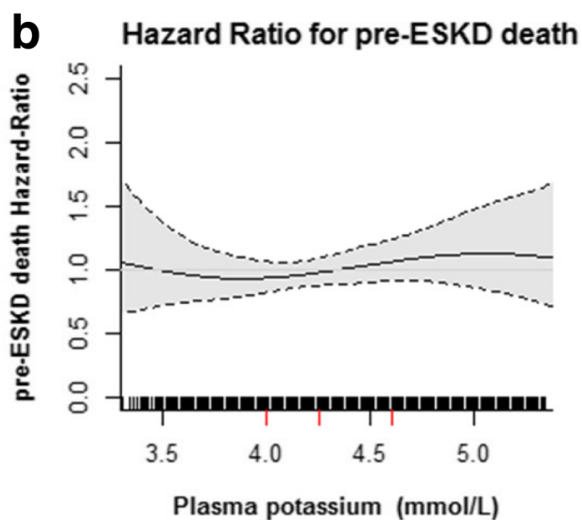

Hazard Ratio for overall death whatever ESKD

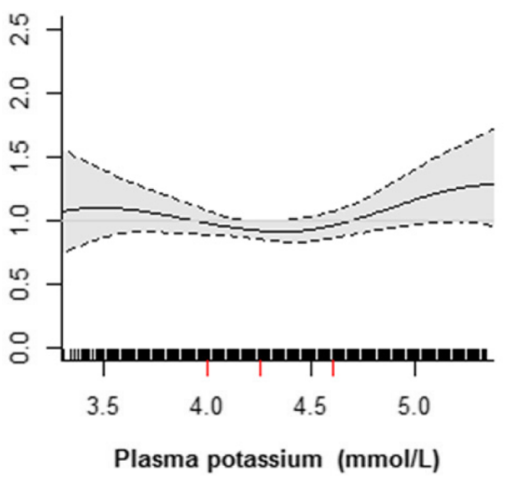

Fig. 1 Estimated adjusted hazard ratio with 95\% confidence intervals for the association of plasma potassium level with end-stage kidney disease $($ ESKD) (a), overall pre-ESKD death (b), and pre-ESKD cardiovascular (CV) death (c) and overall death whatever ESKD (d) using penalized-splines estimator. Hazard ratio (HR) were plotted only for values below 95th percentile

follow-up, were associated with all-cause or CV mortality in this population. A major finding from this selected cohort of patients receiving optimized nephrologist care is that the lack of excess mortality with high $\mathrm{P}_{\mathrm{K}}$ was apparently observed in the absence of reduction in the use of $\mathrm{ACEi}$ or ARBs over time.

Optimal care of patients with CKD stage 3 or higher should involve annual assessment of metabolic and cardiovascular complications and adaptation of medication to achieve recommended therapeutic targets [22]. The NephroTest work-up implemented since 2000 in the three university hospitals in this study sought to improve CKD care by providing comprehensive assessment of CKD complications at yearly intervals together with reminders of current recommended targets. It should be emphasized that the unique design of this study with exclusive participation of patients with optimized nephrology care makes it difficult to compare our results with those from other studies. Moreover, we measured РK which is likely to have resulted in a slight shift towards lower values as compared with other studies using SK. A U-shaped relation has previously been reported between $S_{K}$ and mortality in several

Table 3 Plasma potassium level between the first and second visit

\begin{tabular}{|c|c|c|c|c|}
\hline \multirow[b]{2}{*}{ Plasma potassium at the first visit } & \multicolumn{3}{|c|}{ Plasma potassium $(\mathrm{mmol} / \mathrm{L})$ at the second visit } & \multirow[b]{2}{*}{ Total } \\
\hline & $<4$ & {$[4,5]$} & $>5$ & \\
\hline$<4$ & $186(15.6)$ & $126(10.6)$ & $4(0.3)$ & $316(26.6)$ \\
\hline$[4,5]$ & $111(9.3)$ & $593(49.8)$ & $85(7.1)$ & $789(66.3)$ \\
\hline$>5$ & $7(0.6)$ & $46(3.7)$ & $32(2.7)$ & $85(7.1)$ \\
\hline Total & $304(25.6)$ & $765(64.3)$ & $121(10.2)$ & $1190(100 \%)$ \\
\hline
\end{tabular}



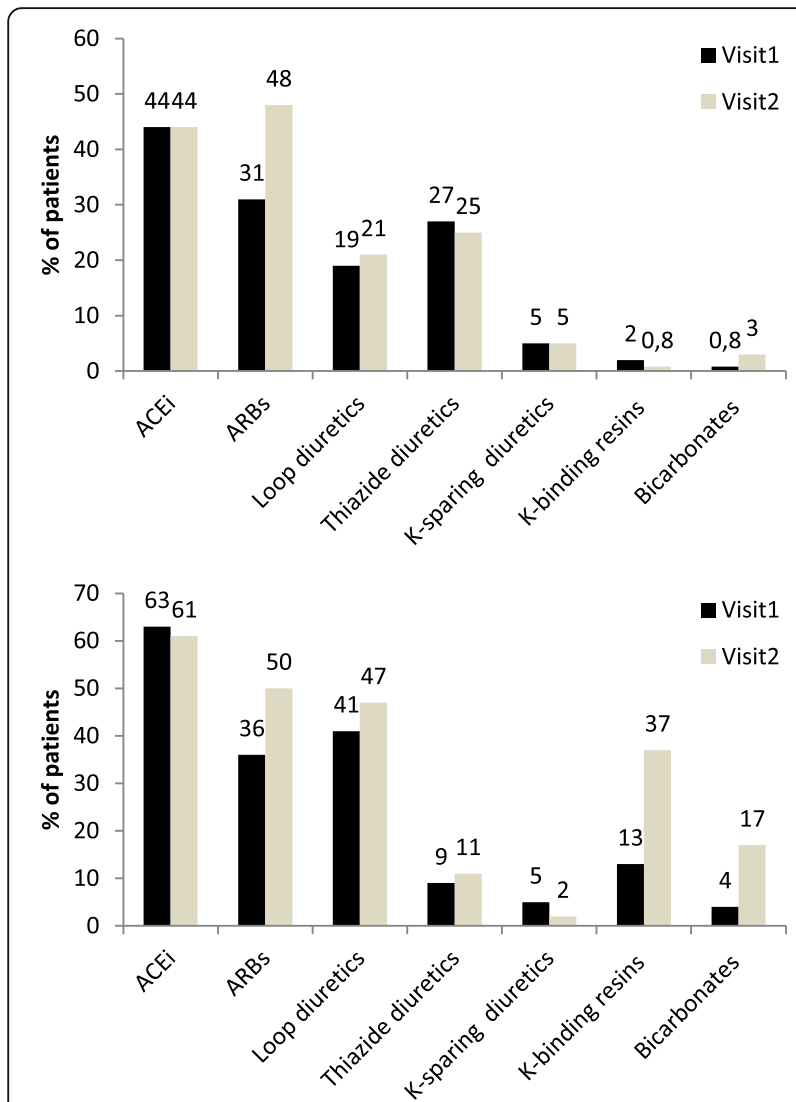

Fig. 2 Treatment use at the first and second visit for patients having change status from low to normal plasma potassium $(A-N=126)$ and high to normal plasma potassium $(B-N=46)$. ${ }^{*} P$-value $<0.05$, ** $<0.01,{ }^{* *}<0.001$

cohorts of HF [13], hypertension [23], and CKD patients $[4,14,15,17]$, but we observed no such association with $\mathrm{P}_{\mathrm{K}}$ in the NephroTest cohort.

Although no causality could be ascertained in this observational setting, we note that $74.4 \%$ of the CKD patients in our cohort were treated with ACEi or ARB at baseline (a higher rate than in the above-mentioned CKD cohorts, where it was 58.0, 59.0, and $62.1 \%$ [14, 15, 17] and $29.0 \%$ [4],), they had a low baseline prevalence of high $\mathrm{P}_{\mathrm{K}}$ and a reinforced follow-up, in that patients agreed to undergo, beyond their routine nephrology care, additional extensive laboratory testing. Strikingly, low $\mathrm{P}_{\mathrm{K}}$ (common at baseline) and high $\mathrm{P}_{\mathrm{K}}$ (uncommon at baseline) were corrected in a substantial number of patients between the first and second NephroTest work-up: management was responsive to test results, as shown by the increased prescriptions for ARBs in patients with low baseline $\mathrm{P}_{\mathrm{K}}$, and the increased prescription for potassium-binding resins and bicarbonate in those with high baseline $\mathrm{P}_{\mathrm{K}}$. Interestingly, the stable ACEi and increased ARB use in these patients suggests that the nephrologists were not reluctant to prescribe drugs that might promote still higher $\mathrm{P}_{\mathrm{K}}$. In contrast, a recent retrospective survey of US CKD patients reported a U-shaped association between $\mathrm{S}_{\mathrm{K}}$ and discontinuation of these medications blocking the reninangiotensin-aldosterone system (RAAS) [4]. It may be that the use of first-generation potassium-binding resins, either sodium-based (e.g., sodium polystyrene sulfonate, SPS) or calcium-based (e.g., calcium resonium), and bicarbonates made the RAAS inhibition sustainable (by taking care of the low $\mathrm{P}_{\mathrm{K}}$ part of the U-shape curve) while avoiding life-threatening high $\mathrm{P}_{\mathrm{K}}$ (by blunting the right-hand side of the U-shaped relation between $P_{K}$ and outcomes). This interesting hypothesis warrants testing in randomized trials.

Only a few studies have observed a higher risk for ESKD associated with high $S_{K}[11,16]$. Our study found a slight but statistically significant excess risk of ESKD at higher $\mathrm{P}_{\mathrm{K}}$ levels, observed only with time-dependent Cox models. Because both $\mathrm{P}_{\mathrm{K}}$ and ESKD risks rise as GFR falls, it is difficult to determine whether this reflects the potential impact of $\mathrm{P}_{\mathrm{K}}$ on CKD progression or residual confounding by mGFR level.

Management of patients with chronic hyperkalemia is currently in the process of changing, and these findings are relevant to these changes [22]. Until recently, recommendations for these patients called for a lowpotassium diet and the elimination of both potassium supplements and drugs, such as NSAIDS, that can compromise renal function. Instead, today, physicians are supposed to begin treatment with a non-potassiumsparing diuretic if indicated or to increase the dose for patients already on a diuretic. Dose reduction or discontinuation of RAAS inhibitors, especially mineralocorticoid receptor antagonists, is also recommended. Patients with chronic hyperkalemia for whom continued use of these drugs is thought necessary, such as those with CKD and/or HF with reduced ejection fraction, can be treated with a potassium-lowering agent such as SPS alone or with sorbitol and the RAASinhibitor (RAASi) treatment continued [24]. Unfortunately, the poor tolerability of available $\mathrm{P}_{\mathrm{K}}$-lowering agents tends to induce poor compliance over the long run. SPS has been available to reduce potassium levels for several decades, but it is poorly tolerated and its use, especially in combination with sorbitol, has been associated with bowel necrosis [25]. Because SPS exchanges $\mathrm{P}_{\mathrm{K}}$ for $\mathrm{Na}+$, it can increase sodium absorption and, therefore, plasma volume, it may be dangerous in patients with volume overload such as those with chronic HF, CKD, and/or salt-sensitive hypertension. The recent availability, at least in the US, of the nonabsorbed potassium-lowering polymer Patiromer and the likely availability within the year of the potassiumbinding agent ZS 9 provide an opportunity to continue RAASi in patients with hypertension [25].(11) Although 
both Patiromer and ZS9 have been shown to be effective in reducing $P_{K}$ to normal levels in patients with hyperkalemia and to be relatively well tolerated, their long-term effectiveness on $\mathrm{CV}$ and renal outcomes with continued RAASi treatment must be evaluated and compared to those outcomes in patients switching to another class of antihypertensive agent [26].

Whether the additional potassium and kidney function monitoring and reminders that were the heart of the NephroTest intervention contributed to blunting the relation between $\mathrm{P}_{\mathrm{K}}$ and the outcomes tested must also be considered. Observational data certainly suggest that implementation of potassium and GFR monitoring is inadequate, even though it is recommended by all guidelines for patients treated with ACEi or ARB [27], or mineralocorticoid receptor antagonists [28].

Major strengths of our study include its large sample size and duration of follow-up, together with a high level of accuracy in patient phenotyping including the use of reference methods for measuring GFR, potassium (in plasma which is preferable to serum), and several biomarkers of metabolic complications, both at baseline and follow-up visits. Several limitations should also be noted, including its observational nature, and the percentage (6.6\%) of patients excluded from the analysis because of baseline GFR $<10 \mathrm{~mL} / \mathrm{min} / 1.73 \mathrm{~m}^{2}$ or loss to follow-up. Although this may have decreased the study power; particularly for extreme $\mathrm{P}_{\mathrm{K}}$ values, it is unlikely to have biased our findings. As discussed above, the NephroTest cohort was highly selected, compared to the overall CKD patient population, a selection that precludes any generalization of our findings. Nevertheless, it was this selected nature of our population that made it possible to identify clinical practice patterns, and it is these that may lead to improved clinical management of dyskalemia in other patients. Finally, because drug doses were not recorded, we cannot document whether or not ACEi or $A R B$ dosage was reduced when not withdrawn in patients with high $\mathrm{P}_{\mathrm{K}}$.

\section{Conclusions}

In this cohort of patients under nephrology care, low $\mathrm{P}_{\mathrm{K}}$ and high $\mathrm{P}_{\mathrm{K}}$ appeared to be managed dynamically over time, that is, with careful attention and responsiveness to the patient's current metabolic status. In this context, neither low nor high $\mathrm{P}_{\mathrm{K}}$ was associated with excess overall and cardiovascular mortality. Our study supports the concept perceived in clinical practice that transient abnormality in potassium levels can be controlled by appropriate interventions, and thus may not necessarily indicate the worse outcome or imply the need for discontinuation of ACE-I or ARB.

\section{Additional files}

Additional file 1: Figure S1. Study flowchart. mGFR, measured GFR; ESKD, end-stage kidney disease. (DOCX $25 \mathrm{~kb}$ )

Additional file 2: Figure S2. Distribution of $P_{K}$ levels $(\mathrm{mmol} / \mathrm{L})$ at baseline. (PNG $16 \mathrm{~kb}$ )

\section{Abbreviations \\ ACEi: Angiotensin converting enzyme inhibitors; ARB: Angiotensin receptor blockers; CKD: Chronic kidney disease; CVD: Cardiovascular disease; ESKD: End-stage kidney disease; HR: Hazard ratio; mGFR: measured glomerular filtration rate; OR: Odds ratio; $P_{k}$ : Plasma potassium; RAAS: Renin angiotensin aldosterone system; RAASi: RAAS inhibitor}

\section{Acknowledgements}

Collaborators in the NephroTest Study Group contributing to data collection are Emmanuel Letavernier, Pierre Ronco, Hafedh Fessi (Hôpital Tenon); Eric Daugas, Caroline du Halgouet (Hôpital Bichat); Renaud de La Faille, Christian d'Auzac, Gerard Maruani, Marion Vallet, Laurence Nicolet-Barousse, Mélanie Roland, and Christian Jacquot (Hôpital Européen G. Pompidou). We thank Jo Ann Cahn for revising the English of this manuscript.

\section{Funding}

The NephroTest cohort study was supported by grants from Inserm GIS-IreSP AO 8113LS TGIR; French Ministry of Health AOM 09114 and AOM 10245; InsermA08022LS; Agence de la Biomédecine R08156LL; AURA, and Roche 2009-152-447G.

\section{Availability of data and materials}

The datasets analysed during the current study are available from the corresponding author on reasonable request.

\section{Authors' contributions}

MF, PH, JPH, FV, ET, JJB, and BS designed the NephroTest cohort and MF, PH, JPH collected data. PR, BS, MM and SW designed the study analyses which were performed by MM and SW. PR, BS and SW drafted the manuscript. MM, $M F, Z M, P H, J P H, F V, E T$, JJB contributed to the interpretation of the study results and revised the manuscript. All authors approved the manuscript.

Ethics approval and consent to participate

All patients provided written informed consent before inclusion. The NephroTest study complied with the Declaration of Helsinki and was approved by an ethics committee (CCTIRS MG/CP09.503).

Consent for publication

Not applicable.

\section{Competing interests}

PR received personal fees (consulting) from Novartis, Relypsa, AstraZeneca, Stealth Peptides, Fresenius, Vifor Fresenius Medical Care Renal Pharma, and CTMA; lecture fees from CVRx; cofounder CardioRenal.

The other authors declare that they have no competing interests.

\section{Publisher's Note}

Springer Nature remains neutral with regard to jurisdictional claims in published maps and institutional affiliations.

\section{Author details}

${ }^{1}$ CESP, Inserm U1018, Univ Paris-Saclay, Univ Paris-Sud, UVSQ, Villejuif, France. ${ }^{2}$ FCRIN INI-CRCT, Paris, France. ${ }^{3}$ Bichat Hospital, Paris, France. ${ }^{4}$ INSERM U1138, Paris, France. ${ }^{5} \mathrm{HEGP}$, Paris, France. ${ }^{6}$ Tenon Hospital, Paris, France. ${ }^{7}$ INSERM UMRS970, Boulogne-Billancourt, France. ${ }^{8}$ Ambroise Paré Hospital, Boulogne-Billancourt, France. ${ }^{9}$ INSERM CIC 1433, Nancy CHRU and University of Lorraine, Nancy, France. 
Received: 18 May 2017 Accepted: 1 September 2017

\section{Published online: 12 September 2017}

\section{References}

1. Brenner BM, Cooper ME, de Zeeuw D, Keane WF, Mitch WE, Parving HH, Remuzzi G, Snapinn SM, Zhang Z, Shahinfar S, et al. Effects of losartan on renal and cardiovascular outcomes in patients with type 2 diabetes and nephropathy. N Engl J Med. 2001;345(12):861-9.

2. Holtkamp FA, de Zeeuw D, de Graeff PA, Laverman GD, Berl T, Remuzzi G, Packham D, Lewis JB, Parving HH, Lambers Heerspink HJ. Albuminuria and blood pressure, independent targets for cardioprotective therapy in patients with diabetes and nephropathy: a post hoc analysis of the combined RENAAL and IDNT trials. Eur Heart J. 2011;32(12):1493-9.

3. Parving HH, Lehnert $\mathrm{H}$, Brochner-Mortensen J, Gomis R, Andersen S, Arner P, Irbesartan in Patients with Type D, Microalbuminuria Study G. The effect of irbesartan on the development of diabetic nephropathy in patients with type 2 diabetes. N Engl J Med. 2001;345(12):870-8.

4. Luo J, Brunelli SM, Jensen DE, Yang A. Association between Serum Potassium and Outcomes in Patients with Reduced Kidney Function. Clin J Am Soc Nephrol. 2016;11(1):90-100.

5. Palmer BF. Managing hyperkalemia caused by inhibitors of the reninangiotensin-aldosterone system. N Engl J Med. 2004;351(6):585-92.

6. Rossignol P, Zannad F, Pitt B, Writing group of 10th Global Cardio Vascular Clinical Trialist forum held on December 6th-7th in Paris F. Time to retrieve the best benefits from renin angiotensin aldosterone system (RAAS) inhibition in heart failure patients with reduced ejection fraction: lessons from randomized controlled trials and registries. Int J Cardiol. 2014;177(3):731-3.

7. Rossignol $P$, Legrand M, Kosiborod M, Hollenberg SM, Peacock WF, Emmett M, Epstein M, Kovesdy CP, Yilmaz MB, Stough WG, et al. Emergency management of severe hyperkalemia: Guideline for best practice and opportunities for the future. Pharmacol Res. 2016;113(Pt A):585-91.

8. Zannad F, Rossignol P, Stough WG, Epstein M, Alonso Garcia Mde L, Bakris GL, Butler J, Kosiborod M, Berman L, Mebazaa A, et al. New approaches to hyperkalemia in patients with indications for renin angiotensin aldosterone inhibitors: Considerations for trial design and regulatory approval. Int Cardiol. 2016;216:46-51.

9. Jain N, Kotla S, Little BB, Weideman RA, Brilakis ES, Reilly RF, Banerjee S. Predictors of hyperkalemia and death in patients with cardiac and renal disease. Am J Cardiol. 2012;109(10):1510-3.

10. Rossignol P, Dobre D, JJ MM, Swedberg K, Krum H, van Veldhuisen DJ, Shi $H$, Messig M, Vincent J, Girerd N, et al. Incidence, determinants, and prognostic significance of hyperkalemia and worsening renal function in patients with heart failure receiving the mineralocorticoid receptor antagonist eplerenone or placebo in addition to optimal medical therapy: results from the Eplerenone in Mild Patients Hospitalization and Survival Study in Heart Failure (EMPHASIS-HF). Circ Heart Fail. 2014;7(1):51-8.

11. Miao Y, Dobre D, Heerspink HJ, Brenner BM, Cooper ME, Parving HH, Shahinfar S, Grobbee D, de Zeeuw D. Increased serum potassium affects renal outcomes: a post hoc analysis of the Reduction of Endpoints in NIDDM with the Angiotensin II Antagonist Losartan (RENAAL) trial. Diabetologia. 2011;54(1):44-50.

12. Bowling CB, Pitt B, Ahmed MI, Aban IB, Sanders PW, Mujib M, Campbell RC, Love TE, Aronow WS, Allman RM, et al. Hypokalemia and outcomes in patients with chronic heart failure and chronic kidney disease: findings from propensity-matched studies. Circ Heart Fail. 2010;3(2):253-60.

13. Vardeny O, Wu DH, Desai A, Rossignol P, Zannad F, Pitt B, Solomon SD. Influence of Baseline and Worsening Renal Function on Efficacy of Spironolactone in Patients With Severe Heart Failure: Insights From RALES (Randomized Aldactone Evaluation Study). J Am Coll Cardiol. 2012;60(20):2082-9.

14. Korgaonkar S, Tilea A, Gillespie BW, Kiser M, Eisele G, Finkelstein F, Kotanko P, Pitt B, Saran R. Serum potassium and outcomes in CKD: insights from the RRI-CKD cohort study. Clin J Am Soc Nephrol. 2010;5(5):762-9.

15. Hayes J, Kalantar-Zadeh K, Lu JL, Turban S, Anderson JE, Kovesdy CP. Association of hypo- and hyperkalemia with disease progression and mortality in males with chronic kidney disease: the role of race. Nephron Clin Pract. 2012;120(1):C8-16.

16. Wang HH, Hung CC, Hwang DY, Kuo MC, Chiu YW, Chang JM, Tsai JC, Hwang SJ, Seifter JL, Chen HC. Hypokalemia, its contributing factors and renal outcomes in patients with chronic kidney disease. PLoS One. 2013;8(7):e67140.

17. Nakhoul GN, Huang H, Arrigain S, Jolly SE, Schold JD, Nally JV Jr, Navaneethan SD. Serum Potassium, End-Stage Renal Disease and Mortality in Chronic Kidney Disease. Am J Nephrol. 2015;41(6):456-63.
18. Glick M. Methodology for potassium analysis. Potassium, its biologic significance. 1983:9.

19. Lum G, Gambino SR. A comparison of serum versus heparinized plasma for routine chemistry tests. Am J Clin Pathol. 1974;61(1):108-13.

20. Moranne O, Froissart M, Rossert J, Gauci C, Boffa JJ, Haymann JP, M'Rad MB, Jacquot C, Houillier P, Stengel B, et al. Timing of onset of CKD-related metabolic complications. J Am Soc Nephrol. 2009;20(1):164-71.

21. Noordzij M, Leffondre K, van Stralen KJ, Zoccali C, Dekker FW, Jager KJ. When do we need competing risks methods for survival analysis in nephrology? Nephrol Dial Transplant. 2013;28(11):2670-7.

22. Group KDIGOKCW. KDIGO 2012 Clinical Practice Guideline for the Evaluation and Management of Chronic Kidney Disease. Kidney Int. 2013;(3):1-150.

23. Krogager ML, Torp-Pedersen C, Mortensen RN, Kober L, Gislason G, Sogaard $P$, Aasbjerg K. Short-term mortality risk of serum potassium levels in hypertension: a retrospective analysis of nationwide registry data. Eur Heart J. 2017;38(2):104-12

24. Pitt B, Rossignol P. Potassium lowering agents: Recommendations for physician and patient education, treatment reappraisal, and serial monitoring of potassium in patients with chronic hyperkalemia. Pharmacol Res. 2017;118:2-4

25. Pitt B, Bakris GL. New potassium binders for the treatment of hyperkalemia: current data and opportunities for the future. Hypertension. 2015;66(4):731-8.

26. Pitt $B$, Rossignol $P$. The association between serum potassium and mortality in patients with hypertension: 'a wake-up call'. Eur Heart J. 2017;38(2):113-5.

27. Raebel MA, McClure DL, Chan KA, Simon SR, Feldstein AC, Lafata JE, Andrade SE, Gunter MJ, Nelson WW, Roblin D, et al. Laboratory evaluation of potassium and creatinine among ambulatory patients prescribed spironolactone: are we monitoring for hyperkalemia? Ann Pharmacother. 2007;41(2):193-200.

28. Cooper LB, Hammill BG, Peterson ED, Pitt B, Maciejewski ML, Curtis LH, Hernandez AF. Consistency of Laboratory Monitoring During Initiation of Mineralocorticoid Receptor Antagonist Therapy in Patients With Heart Failure. JAMA. 2015:314(18):1973-5.

\section{Submit your next manuscript to BioMed Central and we will help you at every step:}

- We accept pre-submission inquiries

- Our selector tool helps you to find the most relevant journal

- We provide round the clock customer support

- Convenient online submission

- Thorough peer review

- Inclusion in PubMed and all major indexing services

- Maximum visibility for your research

Submit your manuscript at www.biomedcentral.com/submit
Biomed Central 